\title{
THE ELECTRIC FURNACE IN INDUSTRIAL
}

\section{CHEMISTRY.}

\author{
BY CHARLES B. JACOBS.
}

In its early days the electric furnace labored under the burden of the prophecies of its wonderful possibilities and products, and seems to have been more or less associated in the popular mind with the production of diamonds from amorphous carbon, the formation of gems and precious stones from cheap and plentiful materials, and other somewhat sensational operations which had a tendency to obscure, for a time, the knowledge of its usefulness in the field of industrial chemistry.

Notwithstanding the fact that DeChalmot, the Cowles brothers and others, had been operating the electric furnace for some years in the production of alloys from very refractory ores, it was not until Acheson produced carbide of silicon, Willson obtained carbide of calcium in commercial quantities, and Moissan published his scientific investigations in Le Four Electrique, that the value of the electric furnace for the production of substances useful in the arts began to be generally recognized.

Since that time, however, its field of usefulness has been steadily increasing until it is now obtaining recognition as an important factor in industrial chemistry.

Reference to the patent lists of the various countries will show an immense variety of electric furnaces, but they may all be classified under three general types which have been modified in numerous ways to meet the special requirements of the various processes for which they are intended.

The three general types of the electric furnace are:

(1) The reflecting are furnace of the Moissan type, in which 
the heat of the arc is projected upon the charge by a reflecting surface.

(2) The direct-heating arc furnace, in which the arc is surrounded by the material treated and imparts its heat directly to the charge.

(3) The incandescent furnace, in which either the charge or the walls of the furnace form a part of the electrical circuit and by the resistance offered to the passage of the current produce the required heating effects.

The direct-heating arc and the incandescent furnace are the types most frequently met with in commercial work.

The electric furnace, of whatever type, is, properly speaking, nothing more than a machine capable of producing a high degree of thermal efficiency, for it is not usual in electric furnace work to depend on the current for any electrolytic action; in fact, the alternating current is more regulable and seems to give better heating effects than direct current. When electrolytic action does come into play, the furnace reverts to the electrolytic cell of the type in which fused substances are electrolyzed, but even here the effects depend solely on thermic conditions. The compounds formed or decomposed by a given expenditure of electrical energy are directly dependent upon and calculable from the heats of formation of the compounds in question, by virtue of the relationship which exists between the voltage, heat of formation of chemical compounds and their electrochemical equivalents.

The true type of electric furnace is purely thermal in its effects and has no concern with electrolytic action.

The quantity of heat which may be liberated per second in an electric furnace varies from a few hundred calories in small laboratory furnaces to many thousand calories in large furnaces of commercial capacity. The intensity of the heat or the temperature which may be obtained in an electric furnace is limited and controlled by various conditions, chief among which are the refractability and heat conductivity, or rather lack of heat conductivity, in the material of which the furnace is constructed.

In furnaces constructed with linings of pure carbon blocks reinforced with some very poor conductor of heat, such as magnesia or chalk blocks, it is possible to obtain a temperature close to $4000 \mathrm{C}$., but at this temperature the purest carbon begins to vaporize.

The temperature to which the charge in the furnace may be 
raised is of course dependent upon the weight and specific heat of the material to be theated, and this data being known, the temperature obtainable may be calculated with some degree of exactness, especially when the duration of the heating is short and the charge is enclosed in furnace walls of very low heat conductivity, so that the heat generated is mainly absorbed by the charge.

It is comparatively easy to operate commercially at temperatures ranging from $2500^{\circ}$ to $3500^{\circ} \mathrm{C}$. and to raise the charge almost immediately to the required temperature. Operating at these high temperatures, which may be constantly maintained until the desired operation is completed, reactions will take place between elements which have apparently no affinity for each other at the temperatures obtainable in ordinary combustion furnaces.

All are more or less familiar with the results obtained by Moissan in his electric furnaces, and Borchers claims to have gone far toward proving that every known oxide may be reduced by carbon in the electric furnace.

Among some of the most striking of the new chemical compounds of the electric furnace are carbide of silicon, carbide of calcium, and the silicides of the alkaline earth metals.

The carbide of silicon, or $\mathrm{SiC}$, or carborundum, as it is commonly called, was discovered by Acheson about 1893. It is the direct combination of two very similar elements and probably has the structure $\mathrm{Si} \equiv \mathrm{C}$, the silicon and carbon being linked together by double bonds. It is only a shade less hard than the diamond and has found a ready market as an abrasive and is being manufactured on a large scale by the Carborundum Company at Niagara Falls. Very little of practical value has been discovered regarding its chemical properties, although it will undoubtedly be found to have some striking and very useful chemical properties which sooner or later will find commercial application of value.

The carbide of calcium, which was first produced commercially by Willson about 1895, we are all familiar with, chiefly from its use in the production of acetylene gas for illuminating purposes. Its importance as a reagent in manufacturing chemistry is, however, becoming recognized, and with the proper investigation of its properties it is only a question of time before its consumption for manufacturing purposes will equal, if not exceed, its present consumption as an illuminant. It is a powerful dehydrating 
agent and possesses the property of extracting water and even the hydroxyl group from other compounds.

The possibility of using calcium carbide as a means of synthetically producing the valuable constituent of coal tar in a pure state, and the compounds of the benzine series in general, is very inviting; a very pure sample of $c$ nthracene, one of the valuable dye products, has been prepared by the Ampere Electrochemical Company, using calcium carbide as the original source of the hydrocarbon.

The carbides of the alkaline earth metals in particular offer a fruitful field for original investigation and synthetic work. The fact that they are unsaturated compounds and are capable of forming further additional prolucts, under the proper conditions, makes them specially attractive.

All the evidence seems to point to $\mathrm{R}<\|_{\mathrm{C}}^{\mathrm{C}}$ (in which $\mathrm{R}$ represents the alkaline earth meal), as the structural formula for the alkaline earth carbides, but two of the eight bonds of the two carbons being satisfied by the bivalent alkaline earth metal; the other six are satisfied by the affinities between the two carbons for each other, which is not a very strong combination. If now this compound be heated in the presence of some element having a stronger affinity for car zon than carbon has for itself, the bonds between the carbons will open, and the new and stronger element will attach itsel to the carbons of the carbide to form a saturated compound. INitrogen, for instance, if passed through heated carbide of bariur under the proper conditions will, at a certain critical temperature, combine with the carbide, forming a cyanide of the barium.

The structural equation probably best explains what takes place:

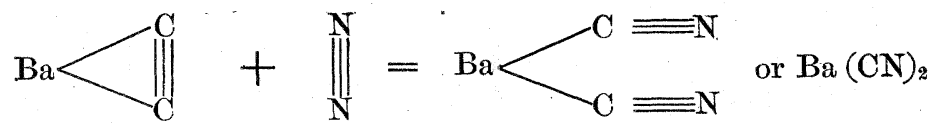

The Ampere Electrochemical Company has taken advantage of this property of the carkides in the production of the 
cyanides of sodium and potassium, barium carbide being used as the absorber of nitrogen derived from the atmosphere, and as the carrier of the cyanogen, which is subsequently converted by ordinary chemical means into sodium or potassium salt, the barium being used over again in the production of more barium cyanide.

Hydrogen, if introduced with heated carbides, should combine in the same manner at some critical temperature, forming, for instance, with calcium carbide, what might be called calcium di-methyl.

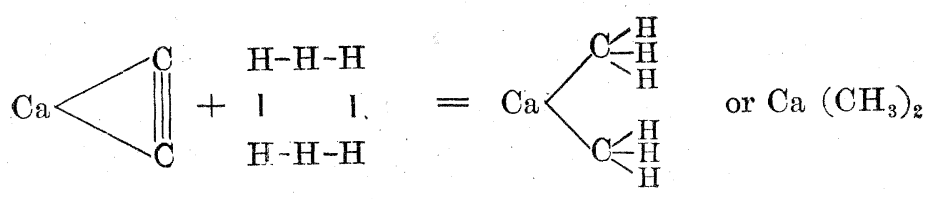

Any of the unsaturated carbides should act in a similar manner.

The silicides of the alkaline earth metals, namely: calcium, barium and strontium, were discovered by the Ampere Electrochemical Company in July, 1899. These compounds which have the formula $\mathrm{Ca} \mathrm{Si}, 2 \mathrm{Ba} \mathrm{Si}$, and $\mathrm{Sr}_{2} \mathrm{Si}_{2}$, respectively, are the silicon analogues of the alkaline earth carbides. The relationship is readily seen when the structural formulæ are compared:

Silicon has replaced the carbon of the carbide, $R$ remaining the same in both compounds.
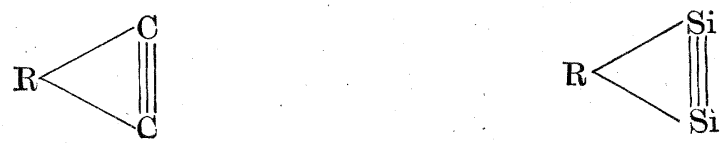

These compounds are formed in the electric furnace under conditions similar to those maintained in the manufacture of alkaline earth carbides, although at a somewhat higher temperature, when the carbonates, oxides, sulphates or phosphates, of the alkaline earth metals are mixed with silica, in which the relative proportions of the alkaline earth metal to the silicon in the mixture is as one to two, and sufficient carbon to effect the reduction is added; or when silicates of the alkaline earth metals in which the molecular relation of the alkaline earth metal to the silicon is as one to two, are mixed with sufficient carbon to 
combine with the oxygen of the silicates and are heated in the electric furnace. These compounds are white or bluish white substances of metallic appearance, and resemble the silicide of aluminium and metallic silicon somewhat in appearance. They possess a distinctly crystalline structure showing plate-like crystals on fracture. They oxidize slowly in the air at ordinary temperatures, and more rapidly under the influence of heat, yielding silicon dioxide and the oxide of the alkaline earth metal. Like the carbides they decompose with water, but yield instead of acetylene, hydrogen in a pure state, which is evolved without. explosion. The following is the reaction between barium silicide and water:

$$
\mathrm{Ba} \mathrm{Si}_{2}+6 \mathrm{H}_{2} \mathrm{O}=\mathrm{Ba}(\mathrm{OH})_{2} 2 \mathrm{Si} \mathrm{O}_{2}+10 \mathrm{H} \text {. }
$$

Calcium and strontium silicide react in the same manner. The calcium compound decomposes very slowly in cold water, but more rapidly in hot water; barium silicide decomposes rapidly in both hot and cold water, while the strontium compound decomposes more rapidly than calcium, but less so than barium silicide.

A1l these compounds produce large volumes of hydrogen in a pure state; when chemically pure the following amounts of hydrogen may be obtained from one pound of silicides on treatment with water:

$1 \mathrm{lb}$. calcium silicide, $18.73 \mathrm{cu}$. ft. of hydrogen

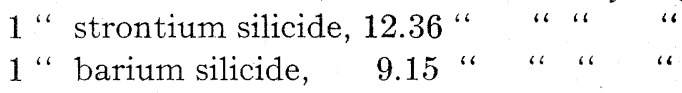

at zero degrees $\mathrm{C}$ and 760 M.M.

The silicides decompose rapidly in dilute acids, the barium compound producing silico-methane and free hydrogen according to the following equation:
$2 \mathrm{BaSi}_{2}+4 \mathrm{HCL}+6 \mathrm{H}_{2} \mathrm{O}=2 \mathrm{BaCl}_{2}+2 \mathrm{SiH}_{4}+4 \mathrm{H}+$ $2 \mathrm{SiO}_{2}+2 \mathrm{H} \mathrm{O}$.

Calcium silicide, strange to say, acts in an entirely different manner when treated with dilute acids and gives rise to the formation of a new chemical compound which has the formula $\mathrm{Si}_{2} \mathrm{H}_{2}$, the reaction which produces it being as follows:

$$
\mathrm{Ca} \mathrm{Si}_{2}+2 \mathrm{HCL}=\mathrm{Ca} \mathrm{Cl}{ }_{2}+\mathrm{Si}_{2} \mathrm{H}_{2}
$$

This compound is the silicon analogue of acetylene, $\mathrm{C}_{2} \mathrm{H}_{2}$, and must therefore be called silico-acetylene, since it bears the same 
relation to silico-methane, $\mathrm{Si} \mathrm{H}_{4}$, as acetylene bears to methane, $\mathrm{CH}_{4}$. It is a yellow crystalline solid, and differs in properties from the compound $\mathrm{Si}_{2} \mathrm{H}_{3}$ which Ogier obtained by sparking silico-methane. The compound of Ogier was unstable and exploded when subjected to a shock. Silico-acetylene is not explosive and is stable at ordinary temperatures. Heated in the air it oxidizes rapidly, giving silicon dioxide and water. When heated in a closed tube, it breaks down into amorphous silicon and free hydrogen. It is insoluble in acids, but when treated with caustic soda and potash solutions it yields hydrogen and a silicate according to the following equation:

$$
\mathrm{Si}_{2} \mathrm{H}_{2}+4 \mathrm{NaOH}+2 \mathrm{H}_{2} \mathrm{O}=2 \mathrm{Na}_{2} \mathrm{SiO}_{3}+10 \mathrm{H} \text {. }
$$

Strontium silicide is remarkable on treatment with dilute acids, from the fact that it follows both calcium and barium in its behavior, yielding a mixture of free hydrogen, silico-methane and silico-acetylene.

The practical applications of the alkaline earth silicides and of silico-acetylene are many and varied, although the compounds are of almost too recent origin to have touched on more than a few of the most apparent of their uses. Barium silicide seems to be rather the most important of the silicides on account of its great activity and the positive nature of all its properties. Strontium would answer as well for most purposes, but the scarcity of strontium compounds makes it somewhat more expensive and difficult to obtain in commercial quantities.

As a hydrogen producer, barium silicide probably offers the cheapest and most convenient source of pure hydrogen in commercial quantities, it being only necessary to introduce the material into an ordinary acetylene gas generator and add cold water to obtain pure hydrogen.

All the silicides are strong reducing agents for both organic and inorganic compounds.

Barium silicide has been used for the reduction of indigo and seems to offer many advantages over zinc dust and Schutzenburger's reagent. It is only necessary to make the indigo blue into a thin paste with water, and introduce the finely ground silicide. The solution of indigo white thus produced is clean and free from impurities and may be applied directly to the fibre of the cloth or substance to be dyed.

For organic compounds in general, when it is of advantage to make reductions in neutral solutions, barium silicide serves the purpose admirably. 
Silico-acetylene may be substituted for barium silicide as a reducing agent when the reductions are carried out in caustic soda or potash solutions.

The silicides of barium and strontium will undoubtedly find many applications as reducing agents in the aniline industry.

One of the large consumers of calcium, as well as barium silicide, will probably be the iron and steel industry. The alkaline earth silicides when melted with iron carrying sulphur and phosphorus have the property of combining with the sulphur and phosphorus, forming sulphides and phosphides of the alkaline earth metal, while the silicon alloys with the iron as silicide of iron. If now the melted mass be blown with air in a steel converter, the sulphides and phosphides of the alkaline earth are oxidized to sulphates and phosphates, while the silicon burns to $\mathrm{SiO}_{2}$ and these impurities rise to the surface as slag, thus freeing the iron or steel of their sulphur and phosphorus. Tests have been made on irons carrying an excess of sulphur and phosphorus in which the last traces of these troublesome impurities were found to have been removed.

The silicides also offer a good field for original investigation. Tucker and Moody, in a paper published in the Journal of the Society of Chemical Industry, October, 1901, on the production of ethylene from inorganic sources, show that when a mixture of barium carbide and barium silicide is melted and the mass treated with water, a gas is produced which contains about $15 \%$ by volume of ethylene, and conclude their paper with the statement that it seems possible by the methods they employed to obtain a product which, on treatment with water, simultaneously produces a mixture of ethylene and acetylene. The ethylene is probably produced by the combination of acetylene and hydrogen rendered nascent at the same instant from the carbide and silicide in. such close contact as to constitute practically a. galvanic couple between the two compounds. This seems to be the most reasonable explanation of the results, since mechanical mixtures of carbide and silicide fail to produce the result.

A practical suggestion offered by the results obtained by Tucker and Moody is that a mixture of acetylene and ethylene: might work to very good advantage in gas engines, particularly for automobiles and launches, and the fact that the gas-producing compounds may be stored and conveniently carried in considerable quantity makes the suggestion rather attractive.

The electric furnace has to its credit the commercial produc-. 
tion of two of the products of nature which are worthy of mention, namely: the production of graphite from amorphous carbon or coal by Acheson, and the production of corundum from amorphous alumina, such as bauxite or other aluminus compounds, invented by the Ampere Electrochemical Co. and now being operated by the Norton Emery Wheel Co. Both of these processes are in commercial operation at Niagara Falls.

The advantage to the consumer of being able to secure manufactured graphite and corundum in unlimited quantity, and of a higher degree of purity than the natural products, at a competitive price, is of inestimable value commercially, especially since the natural sources of both of these products are, as a rule, isolated from the points of consumption and the natural supply is becoming somewhat limited.

So much for the electric furnace and its new products and their probable value in industrial chemistry. The electric furnace, is, as a rule, only of commercial value in carrying out processes or producing results that cannot be obtained in any other way. The enormous consumption and cost of horse power required for chemical work and the consumption of carbon electrodes are items of serious expense. There are, however, a number of instances in which it is of advantage to introduce the electric furnace to replace the ordinary means of bringing about chemical reactions that take place at high temperatures, since it not only shortens the time required for the reactions and thus increases the yield for a given time, but the reactions in many cases take place much more completely. It also offers the additional advantage of placing the heat at the point required. The substitution of the electric furnace for the ordinary means of bringing about heat reactions is, as a rule, merely a problem of economic engineering.

Working under the Readman process, it has been found advantageous to introduce the electric furnaces in the manufacture of phosphorus; the retorts containing the ordinary mixture of phosphorus-bearing material, silica and carbon are heated from within by an arc, and the phosphorus is distilled off and is condensed under water in the ustual manner. The chief feature of the process is economy in breakage of apparatus, due to the external heating by the old method. For the same reason electrical heating has been resorted to in the manufacture of carbon bisulphide. However, the more perfect control of the heat has also been a feature in both of these instances. 
Another important use of the electric furnace in industrial chemistry is its application in the treatment of substances which are difficult to reduce, or which yield only a partial reaction even on long continued treatment at temperatures obtainable in ordinary combustion furnaces.

The old method of working barytes or barium sulphate consists in treating it with coal or coke in reverberatory or retort furnaces. By this method from $65 \%$ to $75 \%$ of the available barium sulphate is converted by reduction into the soluble sulphide of barium, which is then manufactured with other salts of barium.

By a process in operation by the United Barium Company at Niagara. Falls, barytes is treated in the electric furnace, whereby from $97 \%$ to $99 \%$ of the available barium sulphate is converted into soluble form.

The electrical process was invented and developed by the Ampere Electro-chemical Co. Its discovery brought to light a new chemical reaction which takes place beyond the range of temperatures attainable in combustion furnaces.

When a mixture of three molecular equivalents of barium sulphate and one molecular equivalent of barium sulphide are introduced into the electric furnace and the mass brought to a state of fusion, a reaction sets in, according to the following equation:

$$
3 \mathrm{BaSO}_{4}+\mathrm{BaS}=4 \mathrm{BaO}+4 \mathrm{SO}_{2} .
$$

The reaction takes place so completely that not more than two or three per cent. of the unconverted sulphate is left in the charge, and taps have frequently been made from the furnace in which the amount of unconverted barium sulphate present was found to be less than one per cent.

The furnace used in the process, is a new form of continuous electric furnace of the direct-heating arc type and is tapped periodically, similarly to an iron blast furnace. The product tapped from the furnace is dissolved in hot water and the insoluble impurities filtered off. The filtrate, which consists of a saturated solution of barium hydrate containing a small amount of barium sulphydrate, is cooled and the hydrate crystallized out as $\mathrm{Ba}(\mathrm{OH})_{2}+8 \mathrm{H}_{2} \mathrm{O}$. The sulphydrate remaining in the other liquors is separated from the crystals of hydrate and carbonated or converted into some of the acid salts of barium.

Barium hydrate is the chief product of the process, and on ac- 
count of its extreme purity and the price at which it is produced by the electrical process, has met with a ready sale in fields which have heretofore been closed to it on account of price. The old methods of working barytes do not produce barium hydrate at a price which admits of its large consumption in the arts. The fields into which it is finding its way are the white pigment and dry color trades, the purification of water for industrial purposes, and general manufacturing chemistry. Its largest consumption however lies in the beet sugar industry, for the purpose of recovering the sugar which remains uncrystallized in the molasses. In addition to the domestic consumption for this purpose, some large orders have been booked for foreign consumption. So steadily has the demand for this product increased, that after less than a year's operation it has been found necessary to increase the capacity of the plant to a basis of 60 tons of barium hydrate per day.

A further great advantage of the electric furnace is the facility with which operations may be conducted in the presence of various gases so as to bring their chemical actions into play on other substances at a high temperature, or to make them react together, under the influence of the arc. Some rather striking results have been obtained by the use of hydrogen or gases containing a high percentage of it, such as water gas, upon various substances, particularly silicates, at the temperature of the electric furnace.

If kaolin or china clay be raised to the temperature of the electric furnace, and hydrogen be passed through the highly heated silicates, the hydrogen combines with the silicon to form silicon hydride, according to the following equation:

$$
\mathrm{A} 1 \mathrm{Si}_{2} \mathrm{O}_{7}+8 \mathrm{H}=\mathrm{SiH}_{4}+2 \mathrm{H}_{2} \mathrm{O}+\mathrm{Al}_{2} \mathrm{SiO}_{5} \text {. }
$$

The reaction is progressive and if continued the lower silicate first formed will eventually be reduced to aluminium oxide. Metallic aluminium has even been produced by this reaction by continuing the operation with the aluminium oxide, but owing to the high temperature at which the reaction takes place, most of the product is lost by volatilization and the yield of the metal is very small. The lower silicate of aluminium and the oxide formed make very good abrasives with a hardness varying from 8 to 9 in the scale.

The silicide hydrogen issuing from the furnace ignites spontaneously as it comes in contact with the air-producing silicon 
dioxide and water vapor. This silicon dioxide being the product of the combustion of a gas is in a state of extreme subdivision and makes a polishing agent for silver and fine metal work superior to most of the products in use for that purpose.

Probably no field offers so many important commercial problems for solution as the chemistry of the gaseous elements. The possible synthetic combinations of gases and combinations of the gaseous elements with solids, open an almost limitless field for investigation, including as it does the possibility of the synthetic production of breadstuff, starches, gums, carbo-hydrates and the fertilizers. Undoubtedly the electric furnace and the electrolytic cell will play an important part in the solution of many of these problems. Sir William Crookes pointed out the importance of the atmosphere as a source of nitrogen compounds for the production of fertilizers. Crookes, Lord Rayleigh and others have shown experimentally that chemical combination of the nitrogen and oxygen of the air can be made by means of a disruptive discharge. That their results have remained experimental, is largely due to the fact that their conditions lacked one great essential, namely,-energy. The disruptive discharge has little or no energy. To bring about chemical reactions in anything but trivial amounts, requires a definite amount of energy. It remained for Mr. Charles S. Bradley to take the initiative in grasping the fallacy of the experimental results, and to introduce the energy necessary to bring about the combination of the oxygen and nitrogen of the atmosphere in commercial quantity. The work carried on jointly by Messrs. Bradley and D. R. Lovejoy, first in New York City and for the past year at Niagara Falls, has carried the problem of the fixation of atmospheric nitrogen from the realm of experiment and placed it on a basis of commercial development.

Mention of the process is not out of place in this paper, since in reality the apparatus in which the combination of the nitrogen and oxygen takes place may very properly be classed as an electric furnace of the direct-heating arc type, in which the arc imparts its heat directly to the charge, which in this case is dry air.

The Atmospheric Products Co., with which Messrs. Bradley and Lovejoy are connected in this work, depends for the combination of oxygen and nitrogen upon the proper use of a number of extremely high-tension arcs brought into intimate contact with carefully dried air. In addition to the high tension of the arc, sufficient current is carried to furnish the necessary energy for 
raising the molecules of nitrogen and oxygen to their ignition or combining point.

The results so far obtained have demonstrated on a practical scale great economy in the manufacture of nitric acid and the nitrates, also nitrous acid and the nitrates, which makes possible the cheap production of all the commercial products which can be chemically derived from these compounds.

Of the value of the electric furnace in purely scientific investigations little need be said. As some one has already pointed out, in the formation of the metallic carbides and their subsequent decomposition, the electric furnace has offered a very plausible explanation of the occurrence of our natural gas, petroleums and bitumens, while the formation of graphite and corundum has thrown still further light on some of the phenomena and products of the various geological ages. 